\title{
Desafios do atendimento odontológico ao paciente oncológico em tempo de COVID-19
}

\author{
Challenges of dental care to oncological \\ patients in times of COVID-19
}

\author{
Manoela Carrera Martinez Cavalcante Pereira' ${ }^{1}$ \\ Gabriela Botelho Martins ${ }^{2}$ (1) \\ Hayana Ramos Lima ${ }^{3}$ (1) \\ Juliana Borges de Lima Dantas 4 (1) \\ Ana Carla Barletta Sanches ${ }^{5}$ (1) \\ Tila Fortuna Costa Freire ${ }^{6}$ (1) \\ Éder Gerardo dos Santos Leite ${ }^{7}$ (1)
}

\begin{abstract}
${ }^{1}$ Autora para correspondência. Universidade Federal da Bahia (Salvador), Universidade do Estado da Bahia (Salvador). Bahia, Brasil. manoela_p@hotmail.com

Universidade Federal da Bahia (Salvador). Bahia, Brasil. gbmartinsba@gmail.com ${ }^{3}$ Universidade Federal do Sul da Bahia (Teixeira de Freitas). Bahia, Brasil. hayana.lima@ufsb.edu.br ${ }^{4}$ Faculdade Adventista da Bahia (Cachoeira), Universidade Federal da Bahia (Salvador). Bahia, Brasil. judyborges@gmail.com ${ }^{5}$ Universidade Federal da Bahia (Salvador). Bahia, Brasil. acbsanches@hotmail.com 6Universidade Federal da Bahia (Salvador). Bahia, Brasil. tilafortuna@gmail.com 7Programa de Residência Multiprofissional em Saúde da Família - FESFSUS/FIOCRUZ (Salvador). Bahia, Brasil. edergerardo@gmail.com
\end{abstract}

Em dezembro de 2019, na cidade de Wuhan, na China, um surto de pneumonia se iniciou com sintomas de febre, tosse, mialgia e fadigan. O agente infeccioso foi identificado como o novo coronavírus (SARS-CoV-2 - Severe Acute Respiratory Syndrome Coronavirus 2), o sétimo membro desta família de vírus que infecta humanos. Em março de 2020, a infecção pelo SARS-CoV-2 foi decretada como pandemia pela Organização Mundial da Saúde (OMS), recebendo a denominação de COVID-19 (Corona Virus Disease - 2019). Novas evidências sobre a doença permitiram inserir na sintomatologia clínica a presença de anosmia (perda do olfato) e disgeusia/ ageusia (modificação/ perda do paladar) como características importantes e que devem ser investigadas, sem ignorar a possibilidade dos indivíduos assintomáticos, fontes potenciais de infecção. Desde então, uma série de condutas foram instauradas junto à população com o objetivo de manter o controle e diminuição do risco de contágio, que ocorre, principalmente, através da exposição a aerossóis e perdigotos contaminados.

A Odontologia representa uma das áreas com maior chance de risco ocupacional para o contágio pelo SARS-CoV-2, devido ao íntimo contato do dentista com as vias respiratórias do paciente, a frequente exposição à tosse, escarro e fluidos (como saliva e sangue) e a alta produção de aerossóis durante o tratamento. Neste contexto, a Odontologia tem sido desafiada na busca por novas estratégias de biossegurança, na tentativa de promover o atendimento odontológico seguro para o paciente e o profissional师. Assim, a American Dental Association (ADA) A e Conselho Federal de Odontologia do Brasil (CFO) mendam a realização apenas de procedimentos odontológicos de urgência e de emergência durante o período de pandemia. Dentre essas deter- 
minações, deve-se incluir pacientes oncológicos? Seu acompanhamento e tratamento odontológico são de fundamental importância durante a pandemia?

Para o paciente oncológico, a pandemia representa um desafio adicional ao lidar com vários determinantes da doença e do seu tratamento. Em geral, esses pacientes possuem faixa etária avançada e apresentam frequentemente comorbidades concomitantes à neoplasia, como diabetes e hipertensão, além de poderem apresentar desnutrição, hábitos deletérios, como etilismo e tabagismo, e imunossupressão, causada tanto pela própria neoplasia quanto pela terapia antineoplásica. Ainda, os pacientes oncológicos possuem risco elevado de exposição ao SARS-CoV-2, com alto potencial de desenvolvimento de complicações graves da COVID-19, em comparação a indivíduos saudáveis, devido à necessidade de deslocamento frequente para os centros de tratamento oncológico, exposição à radioterapia fracionada, associada ou não a quimioterápicos, e múltiplas consultas diárias com membros da equipe multidisciplinar de atendimento.

Apesar do cenário desafiador da pandemia, o diagnóstico e tratamento do paciente oncológico não podem ser negligenciados ou postergados, sob risco de agravamento da condição clínica, com avanço do estadiamento da doença, aumento das alterações funcionais, limitação das opções de tratamento, piora do prognóstico e diminuição da sobrevida. Desta forma, as consultas para realização do tratamento antineoplásico devem ser mantidas em virtude da gravidade da doença e das possíveis complicações ocasionadas, não só pelo câncer, mas também pelo tratamento oncológico, com necessidade de manejo rápido e imediato.

Até o momento da publicação deste editorial não há um protocolo específico que oriente a realização de tratamento odontológico em pacientes sob terapia antineoplásica durante a pandemia de COVID-19. No entanto, alguns fundamentos são importantes e precisam ser analisados. Quando se trata de pacientes submetidos à radioterapia em região de cabeça e pescoço e/ou quimioterapia, não se deve subestimar que os possíveis efeitos adversos agudos em cavidade oral são capazes de aumentar a taxa de morbimortalidade desses pacientes, a exemplo da mucosite oral, infecções oportunistas, disfagia e distúrbios das glândulas salivares, com consequente hipossalivação e/ou xerostomia, o que necessitaria de acompanhamento contínuo. Todavia, não se pode ignorar que o paciente apresenta mudança não só quantitativa, mas também qualitativa da saliva, com aspecto viscoso e pegajoso, aumentando o reflexo de tosse, o que requer, muitas vezes, a utilização de itens que auxiliam o descarte da saliva, como lenços e guardanapos.

Seguindo este raciocínio, o estudo de Javorkova et al. . comparou pacientes com tumores de mama a pacientes com tumores de pulmão e pescoço, ambos submetidos à radioterapia 3D conformacional, e demonstrou que os últimos possuem uma maior sensibilidade ao reflexo da tosse. Os autores discutem que a relação entre a lesão tecidual pulmonar e/ou das vias aéreas causada pela radioterapia e a tosse ainda é incerta, embora acreditem que se trata de um reflexo à expressão de citocinas pró-inflamatórias, TNF-a, IL-1 a e IL-6, no epitélio brônquico após a radioterapia. Os autores atribuem esse achado à compreensão de que as vias neuronais aferentes vagais, que regulam o reflexo da tosse, possuem terminações amplamente encontradas na mucosa e parede das vias aéreas, desde a sua porção superior, até os bronquíolos terminais e parênquima pulmonar. Dessa forma, acreditam que a tosse funciona como um reflexo defensivo das vias aéreas ao processo inflamatório.

Aliada a essas circunstâncias, a presença de SARS-CoV, agente etiológico da primeira pandemia de coronavírus, foi detectada na saliva antes mesmo do acometimento pulmonar, o que corrobora com o raciocínio da sua fácil transmissibilidade através do fluido salivar ${ }^{7}$. Sabe-se também que o SARS-CoV-2 apresenta afinidade ao receptor ECA-2 (Enzima Conversora de Angiotensina 2), que é expresso por diversas células da mucosa oral e glândulas salivares䏣, o que potencializa a chance de contágio pelo vírus.

Quanto ao controle da mucosite oral, uma das principais complicações agudas do paciente em tratamento oncológico, as terapias medicamentosas com corticóides e anti-inflamatórios podem modular de forma sistêmica o aumento da expressão de ECA-29. Sobre a fotobiomudulação laser, terapia comprovadamente indicada pela MASCC (Multinational Association of Supportive Care in Cancer) para prevenção e controle da mucosite oral|q, ainda não há evidências de que esta conduta interfira na patogênese da COVID-19, 
embora existam indícios de que o laser de baixa potência aumenta a expressão local de ECA-2 ao risco de contaminação do profissional durante as sessões de laserterapia, recomenda-se a suspensão do uso da fotobiomodulação laser de forma profilática e aplicação apenas como analgésico nas lesões de mucosite oral já instaladas, em pacientes de alto risco e em casos selecionados pela equipe multiprofissionall. Apesar de alguns artigos recomendarem o uso de bochecho com colutórios à base de peróxido de hidrogênio a $1 \%$ e solução aquosa de iodo povidine a $0,2 \%$ previamente ao atendimento odontológico para a redução da carga viral em cavidade bucal, não existe evidência científica suficiente que suporte essas recomendações ${ }^{13}$. Assim, diante dessas incertezas, são necessários estudos clínicos randomizados que validem essas condutas.

Refletindo sobre as considerações aqui abordadas, percebe-se que o momento atual de pandemia por COVID-19 evidencia e acentua problemas que são enfrentados há muito tempo e se caracteriza como um desafio adicional para os profissionais da área de saúde e para os pacientes sob diversos aspectos.

A decisão do atendimento ao paciente oncológico deve levar em consideração o risco de evolução e agravamento da doença, e os riscos a que se expõem este paciente e o profissional. Ainda, os serviços de saúde, normalmente já sobrecarregados pelo volume de pacientes, número reduzido de profissionais e baixo quantitativo de insumos, estão atualmente voltados para o atendimento dos infectados pelo vírus, impactando diretamente no quantitativo de vagas, materiais e profissionais disponíveis para as demais necessidades ambulatoriais e hospitalares. Muitos centros cirúrgicos estão sendo utilizados como UTIs para atendimentos de pacientes com COVID-19 e os procedimentos eletivos estão sendo adiados, o que pode retardar ou impedir o tratamento do paciente oncológico. Mesmo em um cenário sem pandemia, esses pacientes já enfrentam ansiedade e sofrimento acentuados diante do risco causado pelo próprio câncer, e, na situação atual, somam-se o medo de contágio aliado à falta de informação e redução da capacidade de atendimentos dos serviços de saúde.
$\mathrm{Na}$ decisão de atendimento, a biossegurança deve ser garantida ao profissional e paciente, minimizando possíveis vias de infecção para ambos. Ainda, há que se cobrar dos serviços de saúde e seus gestores, a garantia de testagem regular para o diagnóstico de COVID-19 em profissionais e pacientes, minimizando transmissão ocupacional, e, como consequência, diminuindo a sobrecarga global do sistema de saúde. Todas estas questões se refletirão em manutenção da qualidade de vida do paciente oncológico, e, por que não dizer, do profissional, pois, para ambos, garantirá segurança e conforto psicológico na continuidade dos atendimentos realizados.

Concluímos ressaltando que, a despeito do fato da pandemia por COVID-19 causar impacto populacional, este será sentido de forma mais significativa pelo paciente com câncer, em especial os idosos, que tendem a apresentar alto risco de infecção e um pior prognóstico da doença. As sociedades de classe relacionadas à oncologia de diversos países publicaram diretrizes para o atendimento desses pacientes, considerando as especificidades dos respectivos sistemas de saúde e a adoção de medidas de mitigação e controle da doença, como o distanciamento social Assim, ainda não há um consenso sobre as condutas a serem implementadas quanto à tomada de decisões pelos profissionais. $O$ uso de telemedicina, bem como o adiamento de consultas não urgentes pelos oncologistas, vem sendo sugerido sempre que possível. Conselho semelhante pode ser dado ao profissional da Odontologia, avaliando a real necessidade de manutenção dos atendimentos, sem que gerem prejuízo ao paciente e garanta a segurança de todos, utilizando o bom senso para a manutenção do equilíbrio entre a necessidade de intervenção e a menor exposição ao risco de infecção.

\section{Agradecimentos}

Fundação de Amparo à Pesquisa do Estado da Bahia (FAPESB) RED_0025/2014 


\section{Referências}

1. Zhu N, Zhang D, Wang W, Li X,Yang B, Song J et al. A novel coronavirus from patients with pneumonia in China, 2019. N Engl J Med. 2020;382:727-33. doi: 10.1056/NEJMoa2001017

2. Gamio $L$. The workers who face the greatest coronavirus risk. The New York Times [Internet]. 2020. [cited 2020 Apr 23]. Available from: https://www.nytimes.com/interactive/2020/03/15/ business/economy/coronavirus-worker-risk.html

3. Peng X, Xu X, Li Y, Cheng L, Zhou X, Ren B. Transmission routes of 2019-nCoV and controls in dental practice. Int J Oral Sci. 2020;12(1):9. doi: 10.1038/s41368-020-0075-9

4. American Dental Association. ADA develops guidance on dental emergency, nonemergency care: recommendations part of dentists' response over COVID-19 concerns. [Internet]. 2020. [cited 2020 Apr 23]. Available from: https://www.ada.org/ en/ publications/ada-news/2020-archive/march/ada-develop guidance-on-dental-emergency-nonemergency-care

5. Conselho Federal de Odontologia. Recomendações para Atendimentos Odontológicos em Tempos de Covid-19. [Internet]. 2020. [acesso em 2020 mar. 19]. Disponível em: https://bit. ly/3epK8Bo

6. Javorkova N, Hajtmanova E, Kostkova L, Zamecnik L, Pecova $\mathrm{R}$, Hanacek J et al. Changes of cough reflex sensitivity induced by cancer radiotherapy of chest and neck regions. J Physiol Pharmacol. 2006;57(Suppl 4):157-63.

7. Wang WK, Chen SY, Liu IJ, Chen YC, Chen HL, Yang CF et al. Detection of SARS-associated coronavirus in throat wash and saliva in early diagnosis. Emerg Infect Dis. 2004;10(7):1213-1219. doi: 10.3201/eid1007.031113

8. Liu L, Wei Q, Alvarez X, Wang H, Du Y, Zhu H et al. Epithelial cells lining salivary gland ducts are early target cells of severe acute respiratory syndrome coronavirus infection in the upper respiratory tracts of rhesus macaques. J Virol. 2011;85(8):4025-30. doi: 10.1128/JVI.02292-10

9. Keidar S, Gamliel-Lazarovich A, Kaplan M, Pavlotzky E, Hamoud $S$, Hayek $T$ et al. Mineralocorticoid receptor blocker increases angiotensin-converting enzyme 2 activity in congestive heart failure patients. Circ Res. 2005;97(9):946-53. doi: 10.1161/01. RES.0000187500.24964.7A

10. Zadic Y, Arany PR, Fregnani ER, Bossi P, Antunes HS, Bensadoun RJ et al. Systematic review of photobiomodulation for the management of oral mucositis in cancer patients and clinical practice guidelines. Support Care Cancer. 2019;27(10):3969-3983. doi: 10.1007/s00520-019-04890-2

11. Manchini MT, Serra AJ, Feliciano RS, Santana ET, Antônio EL, Carvalho PTC et al. Amelioration of cardiac function and activation of anti-inflammatory vasoactive peptides expression in the rat myocardium by low level laser therapy. PLoS One. 2014;9(7):e101270. doi: 10.1371/journal.pone.0101270
12. Chaves ALF, Castro AF, Marta GN, Castro Junior G, Ferris RL, Giglio RE et al. Emergency changes in International Guidelines on Treatment for Head and Neck Cancer Patients During the COVID-19 Pandemic. Oral Oncol. 2020;107:104734. doi: 10.1016/j. oraloncology.2020.104734

13. Franco JB, Camargo AR, Peres MPSM. Cuidados odontológicos na era do COVID-19: recomendações para procedimentos odontológicos e profissionais. Rev Assoc Paul Cir Dent. 2020;74(1):18-21.

14. Desideri I, Pilleron S, Battisti NML, Gomes F, Glas N, Neuendorff NR et al. Caring for older patients with cancer during the COVID-19 pandemic: A Young International Society of Geriatric Oncology (SIOG) global perspective. J Ger Oncol. 2020. doi: 10.1016/j.jgo.2020.05.001 